\title{
Role of desert pavements in water infiltration on fluvial fan surfaces in desert ecosystems
}

\author{
Dejin Wang ${ }^{1}$, Wenzhi Zhao ${ }^{1}$, zhou hong ${ }^{2}$, and Weicheng Luo ${ }^{1}$ \\ ${ }^{1}$ Northwest Institute of Eco-Environment and Resources \\ ${ }^{2}$ Northwest Normal University
}

July 23, 2020

\begin{abstract}
Desert pavements are the common features widespread in arid region, which are important for regulating the ecological and hydrologic processes. However, few studies focused on the role of water movement in maintaining ecologic function in desert pavement landscapes. This study determined the role of desert pavements in water infiltration on fluvial fans, which were reflected by characteristics of desert pavements and infiltration parameters in the middle reaches of Hexi Corridor. Six sites (i.e. one site in hill slope and other five sites in the piedmont) were selected for surveying soil properties within a 50-cm depth soil profile and measuring sorptivity (S), initial water infiltration (ii), steady-state infiltration rate (is) and infiltration time (T) in crust and scalped crust conditions under 5 -cm pressure head. The results indicated that desert pavement surfaces were covered by a thin layer of protective crusts, which were primarily composed of fine earth (56.94\%) and fine-medium gravel (40.46\%). Although characterized by a big range of gravel coverage (19.48\%-97.63\%), the crusts had small gravels (mean size: $0.58 \mathrm{~cm}$ ) and extremely low soil moisture content (SMC; less than 1.30\%), which two parameters did not significantly differ from each site in fluvial fans. The crusts were effective in restricting water infiltration capacity. When the crusts were scalped, the S, ii and is would improve 1.6, 1.7 and 1.6-fold, respectively. These three parameters significantly increased with gravel coverage and medium gravels, but significantly decreased with crust thickness and fine gravels. Desert pavements were closely with water regulation in arid systems, reflecting the vegetation distribution. This study highlights that desert pavements have a strong impact on water infiltration to function as regulating water resource and supplying water for vegetation growth.
\end{abstract}

\section{Data Availability Statement}

The data that support the findings of this study are available from the corresponding author upon reasonable request.

\section{Hosted file}

Main Document.docx available at https://authorea.com/users/345487/articles/471708-role-ofdesert-pavements-in-water-infiltration-on-fluvial-fan-surfaces-in-desert-ecosystems

\section{Hosted file}

Table1.xlsx available at https://authorea.com/users/345487/articles/471708-role-of-desertpavements-in-water-infiltration-on-fluvial-fan-surfaces-in-desert-ecosystems

\section{Hosted file}

Table 2.xlsx available at https://authorea.com/users/345487/articles/471708-role-of-desertpavements-in-water-infiltration-on-fluvial-fan-surfaces-in-desert-ecosystems

\section{Hosted file}


Table 3.xlsx available at https://authorea.com/users/345487/articles/471708-role-of-desertpavements-in-water-infiltration-on-fluvial-fan-surfaces-in-desert-ecosystems

\section{Hosted file}

Table 4.xlsx available at https://authorea.com/users/345487/articles/471708-role-of-desertpavements-in-water-infiltration-on-fluvial-fan-surfaces-in-desert-ecosystems

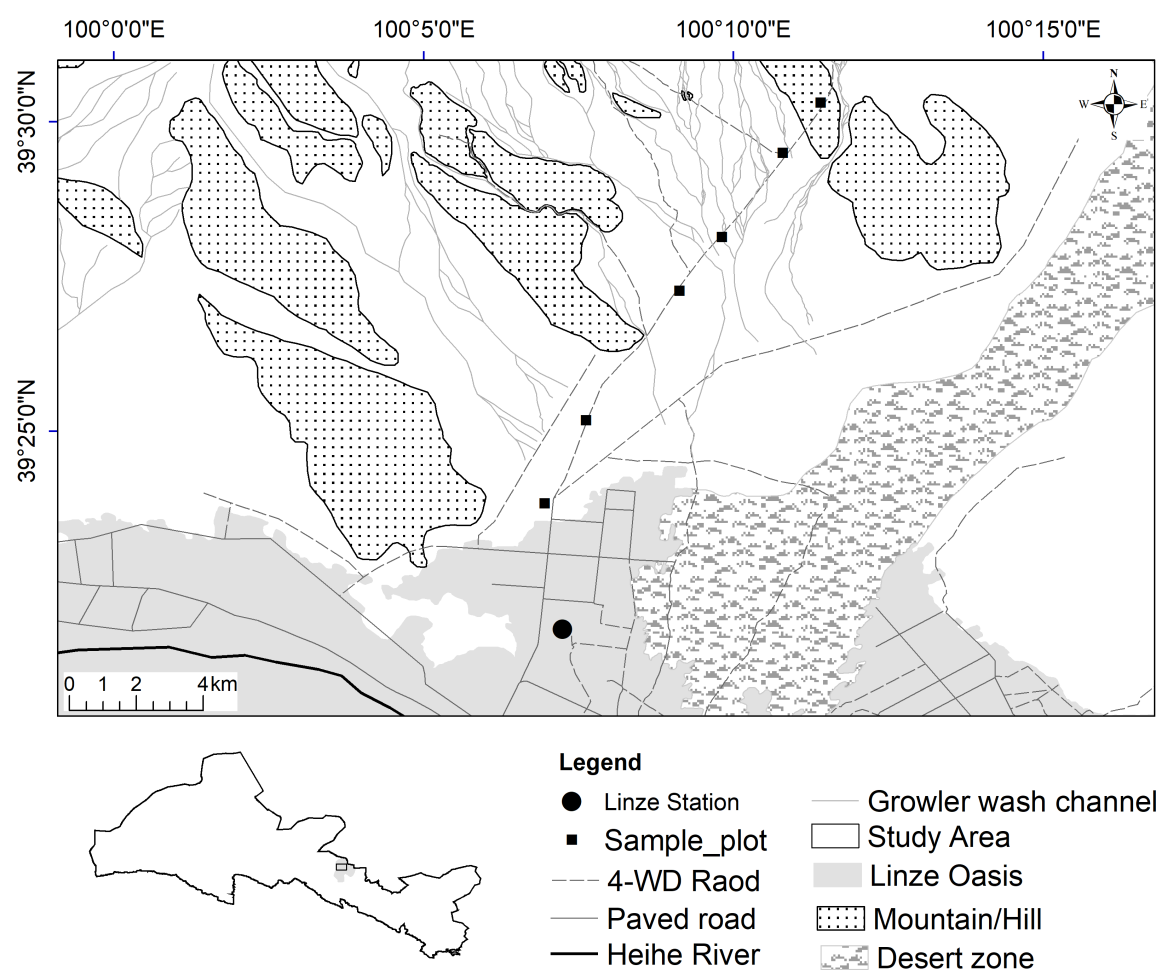




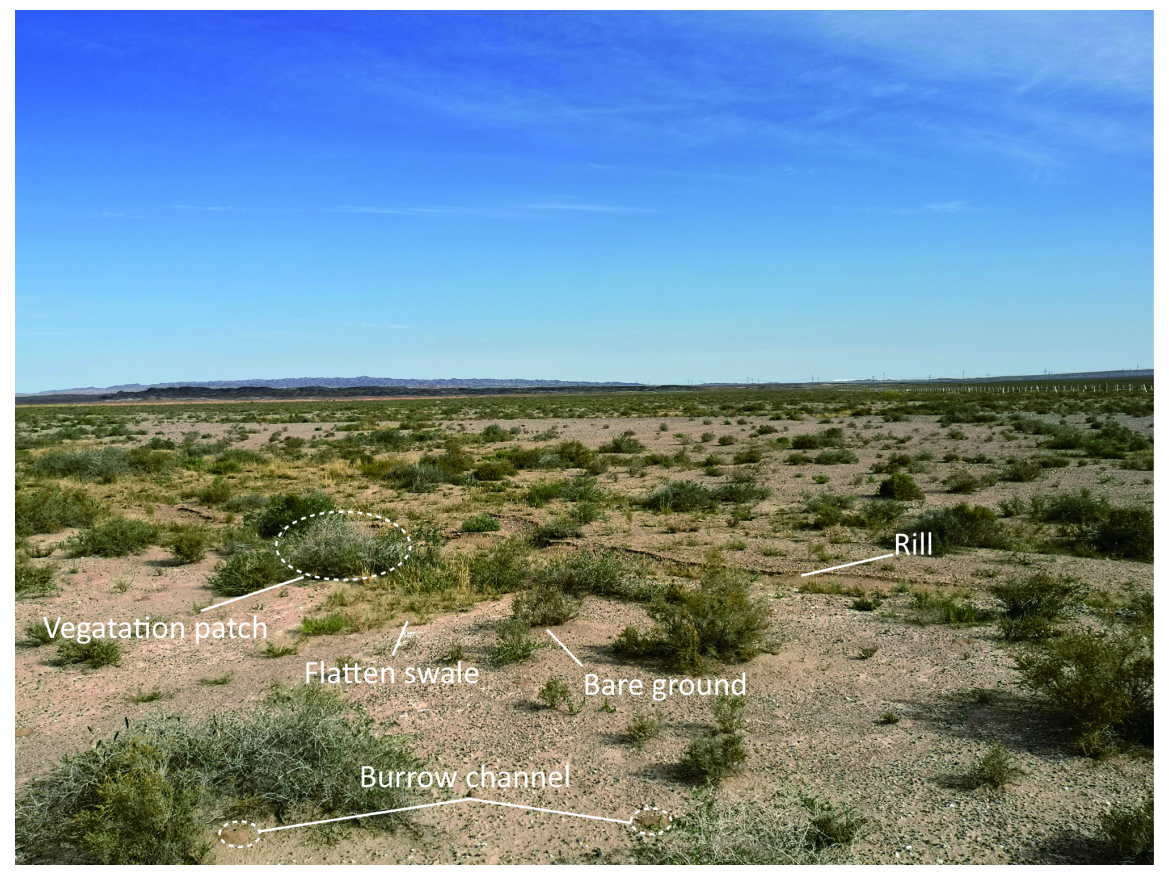




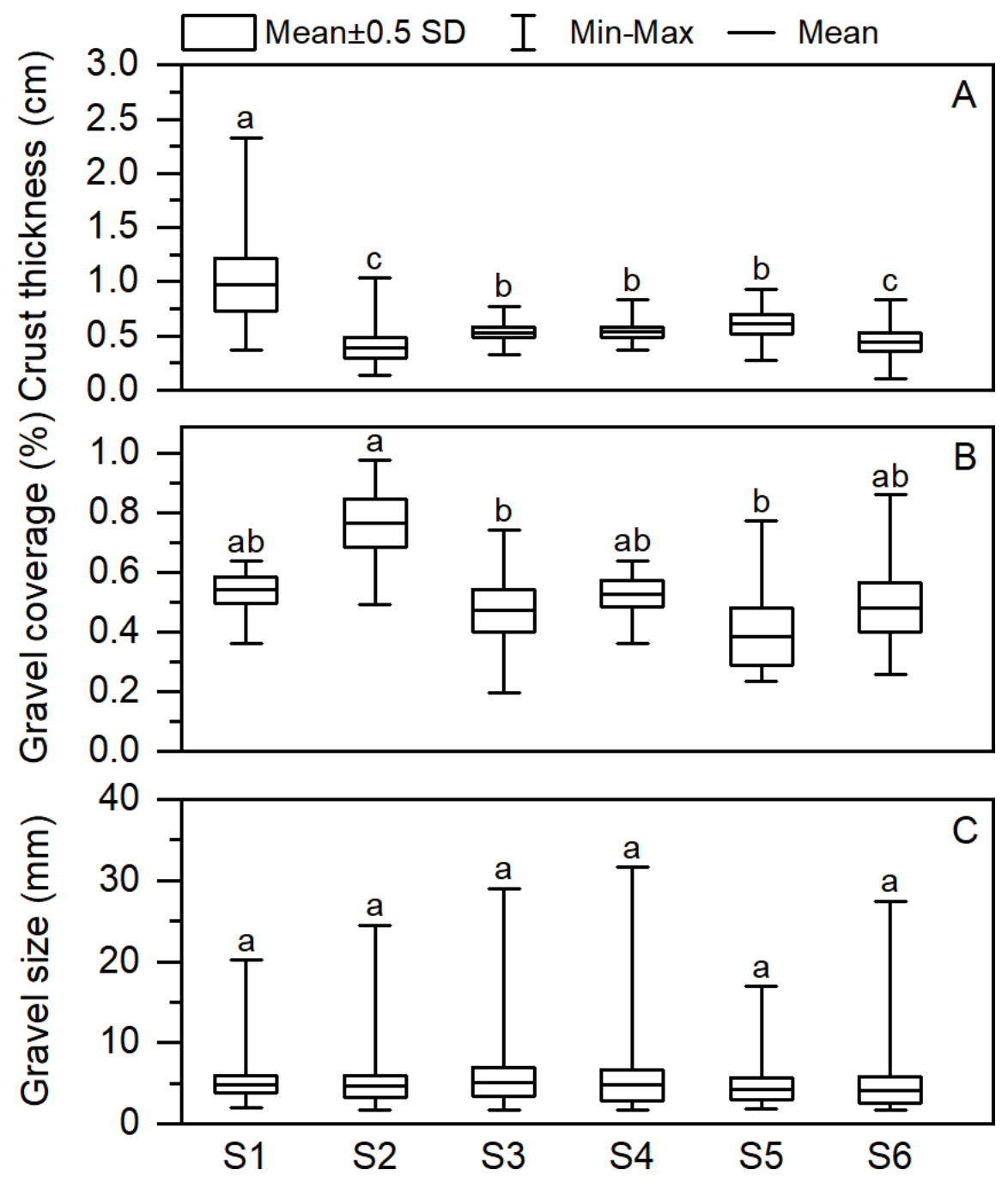




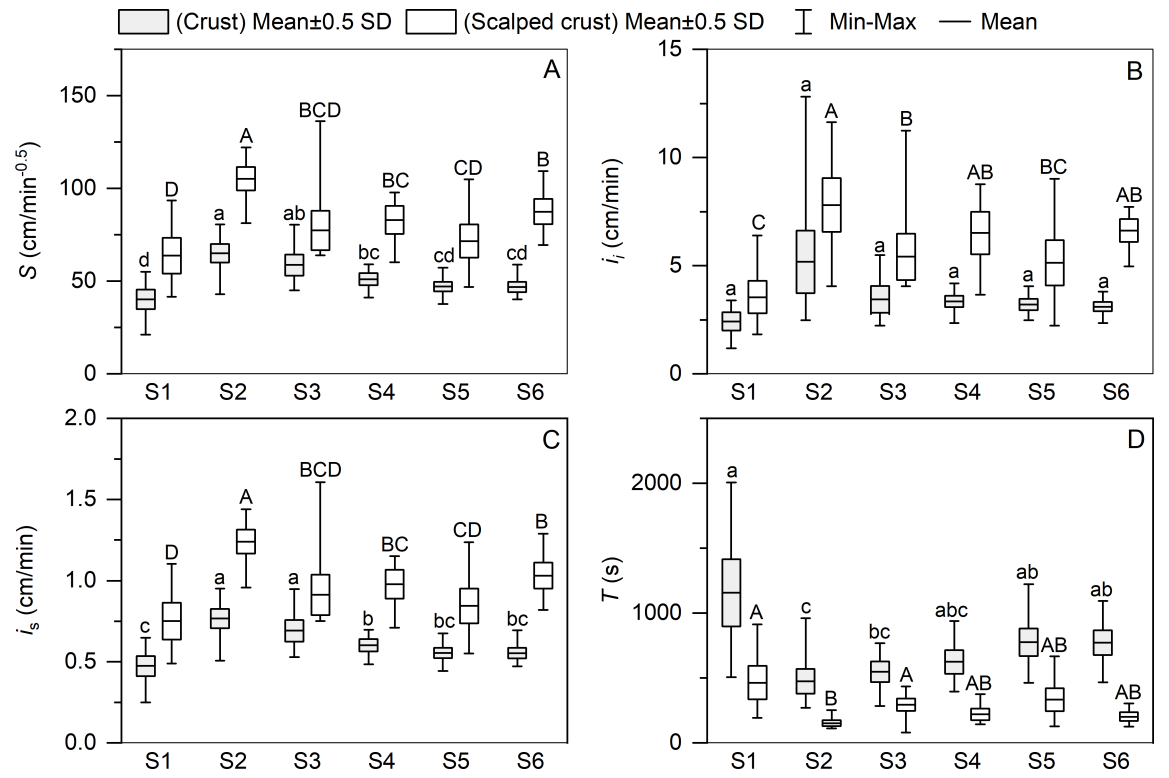

